\title{
Acute Effects Of Resistance Exercise On Heart Rate Variability In Cardiopathic Patients: Cross-Sectional Study
}

\author{
Ana Clara Campagnolo Real Gonçalves ${ }^{1,3}$, Carlos Marcelo Pastre ${ }^{2}$, \\ Vitor Engrácia Valenti ${ }^{1,3}$, Luiz Carlos de Abreu ${ }^{3}$, Luiz Carlos Marques Vanderlei
}

\section{Abstract}

Background: Resistance exercise is used in clinical practice to improve muscle strength and resistance of patients with heart disease. However, it lacks studies regarding its acute effects on cardiac autonomic modulation. This cross-sectional study has aimed to evaluate the acute effects of resistance exercise on heart rate variability (HRV) in cardiopathic patients.

Methods: We investigated 15 volunteers $(63.8 \pm 10.7$ years old; $29.9 \pm 4.32 \mathrm{Kg} / \mathrm{m}^{2}$ ), which were submitted to one maximal repetition (1RM) of knee extension and to the acute interventions with of $40 \%$ and $80 \%$ of 1 RM, with minimal intervals of 48 hours. HRV was analyzed in the SDNN, RMSSD, Poincaré Plot, HF, LF, and LF/HF ratio indexes. We evaluated HRV in the periods of rest $(10 \mathrm{~min})$ and recovery (60 minutes, divided into 6 windows).

Findings: No differences were observed between the immediate recovery and rest periods for all indexes. We observed increase in all indexes after 20 minutes of recovery. No differences were verified between the different protocols.

Conclusion: A single acute session of resistance exercise in different intensities did not change the cardiac autonomic modulation.
1 Programa de Pós-Graduação em Fisioterapia - UNESP - Univ Estadual Paulista, Presidente Prudente, SP, Brazil.

2 Departamento de Fisioterapia, UNESP Univ Estadual Paulista, Presidente Prudente, SP, Brazil.

3 Laboratório de Delineamento de Estudos e Escrita Científica - Departamento de Saúde da Coletividade, Faculdade de Medicina do $A B C$, Santo André, SP, Brazil.

Contact information:

Ana Clara Campagnolo Real Gonçalves.

UNESP/FCT - Departamento de Fisioterapia. Rua: Roberto Simonsen, 305 Centro Educacional Caixa Postal: 467 CEP: 19060-900 Presidente Prudente - SP

”claracamp@gmail.com

Keywords

Muscle strength; Heart rate; Autonomic nervous system 


\section{Introduction}

The reduction of muscle mass due to age and physical inactivity is a clinical relevant factor for cardiopathic subjects [1-4]. It impairs common daily routine and professional activities. Thus, it has been included strength training in cardiac rehabilitation programs in order to improve muscle strength and functional capacity in submaximal activities [5-9].

During physical exercise and its recovery period, the autonomic nervous system (ANS) through the stimulation or inhibition of the sympathetic and parasympathetic branches promotes rapid adjustments in the cardiovascular system to maintain circulatory homeostasis. However, the magnitude of these adjustments to the resistance exercise is proportional to specific factors such as static and dynamic components, duration and intensity of exercise $[10,11]$. Therefore, it deserves attention.

In pathological conditions such as heart diseases, physical exercise may induce different autonomic cardiac responses and induce damage in the adaptation of the cardiovascular system against the exercise, which makes this population more susceptible to complications. The literature described those symptoms in myocardial ischemia, left ventricular dysfunction and cardiac arrhythmias [12-14]. It is believed that the acute performance of resistance exercise at high intensities increase the possibility of these complications $[5,6,11]$.

An efficient way to evaluate the influence of the ANS on the heart is the heart rate variability (HRV) analysis. It is a non-invasive and reproducible tool of easy application, allowing investigating the role of ANS in many conditions, including during and after exercise [15-17].

The prescription of resistance exercise is important for cardiopathic subjects [5-9]. Nevertheless, we should be careful regarding its risks on the cardiovascular complications during and after resistance exercise [12-14], mainly if acutely applied and without safe criteria for prescription [5-6, 11]. In addition, it lacks in the literature studies regarding resistance exercise intervention in cardiac patients with respect to cardiac autonomic modulation.

Therefore, we aimed to evaluate the effects of acute resistance exercise on HRV in cardiopathic subjects.

\section{Methods}

\section{Study population}

This paper is a transversal clinical trial. The subjects were males diagnosed with primary ischemic coronary artery disease and presented preserved left ventricular function [18], which was confirmed by echocardiogram examination. Subjects were invited to participate in a supervised cardiovascular rehabilitation program.

The demographic and clinical profiles of the study population are listed in Table 1.

Among 47 participants, 17 volunteers were eligible to participate in the experimental protocol (Table 1). Inclusion criteria included: nonsmokers, no alcohol use, no use of drugs that influence cardiac autonomic modulation, continued use of drugs prescribed by the physician in charge of the volunteer, and patients who presented limitations to perform resistance exercise, such as exacerbation of chronic orthopedic disease or recent surgery.

Table 1. Demographic and clinical profile of the volunteers.

\begin{tabular}{|l|c|}
\hline \multicolumn{1}{|c|}{ Demographics Profile } & Percent \\
\hline School Degree & \\
\hline Incomplete Elementary School & $26.67 \%$ \\
\hline Complete Elementary School & $33.33 \%$ \\
\hline Current Ocupation & \\
\hline Retired & $40 \%$ \\
\hline Active & $60 \%$ \\
\hline Cardiovascular risk factors \\
\hline Positive familiar history & $60 \%$ \\
\hline Arterial Hypertension & $93.3 \%$ \\
\hline Dyslipidemia & $33.33 \%$ \\
\hline
\end{tabular}




\begin{tabular}{|l|c|}
\hline Obesity & $40 \%$ \\
\hline Ex-smokers & $26.7 \%$ \\
\hline Stress & $40 \%$ \\
\hline Diabetes & $33.33 \%$ \\
\hline Musculoskeletal injuries & $66.7 \%$ \\
\hline Drugs & \\
\hline Antiplatelet & $93.3 \%$ \\
\hline Antihypertensive & $20 \%$ \\
\hline Beta blockers & $60 \%$ \\
\hline Angiotensin converting enzyme & $53.3 \%$ \\
\hline inhibitor & $20 \%$ \\
\hline Coronary or peripherl vasodilators & $20 \%$ \\
\hline Calcium channel inhibitors & $93.3 \%$ \\
\hline Statins & $46.7 \%$ \\
\hline Anxiolytics or antidepressants & $26.7 \%$ \\
\hline Antiulcer & $33.33 \%$ \\
\hline Oral hypoglycemic & $13.3 \%$ \\
\hline Diuretics & $13.3 \%$ \\
\hline Class III antiarhythmic & \\
\hline
\end{tabular}

Two patients were excluded during the experimental protocol, because they started to use specific drugs for thyroid disorders, which influences
HRV. The drug was recommended by their physician. Therefore, the total sample of this study was 15 subjects with a mean age of $63.8 \pm 10,72$ years, and body mass index of $29.94 \pm 4.32 \mathrm{~kg} /$ $\mathrm{m}^{2}$ (Figure 1).

It should be noted that there was a wide range of 1 to 17 years in the duration between the time subjects were diagnosed with an acute coronary event, Stable Angina or Myocardial Infarction, and the time of the intervention.

All volunteers were informed about the procedures and objectives of this study and, after agreement, they signed a consent form. All procedures performed in our study were approved by the Ethics Committee in Research of the Faculty of Science and Technology (FCT/UNESP, Number 19/2009).

\section{Initial evaluation}

Before the onset of the experimental procedure the subjects were asked about their personal data and routine medications. Subsequently, we also measured blood pressure, heart rate, as well as body weight and height in order to calculate the body mass index (BMI). The BMI calculation was calculated as BMI = weight/height [2]. Height and weight

Figure 1: Flow diagram summarizing the procedure for selection of studies for review.

It was not included 30 volunteers, according to the selection criteria.
47 cardiophatic included in PRCV Male Preserved EF

17 subjects

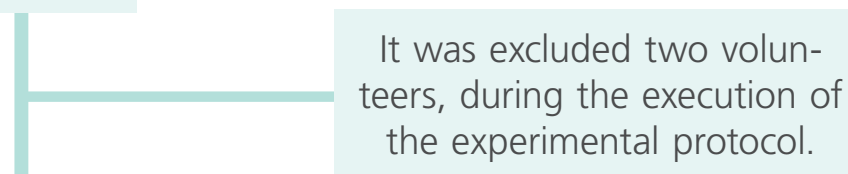

15 volunteers

$63.8 \pm 10.72$ years

$29.94 \pm 4.32 \mathrm{~kg} / \mathrm{m}^{2}$ 
were measured through a stadiometer (ES2020 Sanny, Brazil) and a digital scale (TIN brand MAXIMA 00139, Brazil), respectively. Blood pressure (BP) was measured in compliance with the criteria established by the VI Brazilian Guidelines of Hypertension [19], through an aneroid sphygmomanometer (Welch Allyn - Tycos, New York, USA) and a stethoscope (Littmann, Saint Paul, USA). Heart rate (HR) was measured through Polar S810i (Polar Electro, Kempele, Finland).

After the initial assessment we explained individually to all the volunteers the necessary procedures which we will be using for data collection. We also oriented them regarding the importance of abstinence from some drinks (coffee, soda, chocolate and tea) and the maintenance of the usual practice of physical activity during the protocols.

All volunteers underwent an experimental protocol divided into three stages with a minimum interval of 48 hours between the protocols in order to allow their recovery [20]:

I) One maximum repetition test (1RM): this test was performed to determine the maximum work load and whether to use $40 \%$ or $80 \%$ of $1 \mathrm{RM}$ for the loads used in the following steps.

II) Endurance protocol: the volunteers were submitted to a load equivalent to $40 \%$ of 1 RM, followed by 60 minutes of recovery.

III) Resistance protocol: the volunteers were submitted to a load equivalent to $80 \%$ of 1 RM, followed by 60 minutes of recovery.

Before each protocol the volunteers performed 10 repetitions for heating the specific body segment [21] with minimal resistance of the pulleys system (7 kg).

\section{Stage I - Maximal repetition test}

To define the load used during the endurance and resistance protocols, the volunteers performed 1RM test during knee extension [7, 20-23] through a leg extension equipment (Pulley system, Ipiranga, Academy Hard, São Paulo, Brazil).
During the maximal test, volunteers were monitored through the DIl derivation multiparametric monitor (Active ECAFIX Funbec - Transform Advanced Technology Ltd., Sao Paulo, Brazil). Five electrodes were placed on the chest: the first was placed below the sternal extremity of the clavicle and the following electrodes were placed on the same places of the V2, V5, V6 and V5R local derivations [24].

\section{Stage II and III - Endurance and resistance protocol}

Acute interventions were performed in the second and third steps: the endurance protocol $40 \%$ of 1RM, 2 sets, 20 repetitions with 1 minute of interval between each set) and the resistance protocol (80\% of 1RM, 2 sets, 8 repetitions with 1 minute of interval between each set). The order was defined by random manual draw of cards. During the execution of the movements it was not allowed to perform Valsalva maneuver, because the patients were instructed to exhale during the concentric phase of exercise [20, 21, 23].

Prior to the protocols the heart monitor strap was placed on each subject's thorax over the distal third of the sternum. The heart rate receiver Polar S810i heart rate (Polar Electro, Finland) was placed on the wrist. This equipment has been previously validated for beat-by-beat measurements and for HRV analysis [25]. After placing the heart rate monitor strap the volunteers remained at rest and in the supine position, breathing spontaneously for 20 minutes in a quiet environment with controlled temperature $\left(21^{\circ} \mathrm{C}-23^{\circ} \mathrm{C}\right)$ and humidity (40\%-60\%). The volunteers were then referred for leg extension in order to perform the protocols described above. They were finally returned to the initial environment where they remained for another hour at rest, under the same conditions for analysis of the recovery period.

\section{Heart rate variability analysis}

For HRV analysis, heart rate was recorded beat by beat during the entire protocol with a sampling rate 
of $1000 \mathrm{~Hz}$. The series of RR intervals went through a digital filtering (Polar Precision Performance), complemented by manual filtering to eliminate premature ectopic beats and artifacts, and only series with more than 95\% sinus beats were included in the study [26]. The HRV analysis software - Version 2.0 was used to determine all indices [27].

The following periods were considered for HRV analysis: initial rest [10 intermediate minutes during the first 20 minutes (TO)], and recovery period [60 minutes, divided into six moments of 10 minutes, each window was individually analyzed (T1, T2, T3, T4, T5 and T6)] [28].

The HRV analysis was performed by using linear methods (time and frequency domains). In the time domain we used the following indexes: RMSSD (root mean square of the squared differences between adjacent normal RR intervals in a time interval, expressed in milliseconds) and SDNN (standard deviation of the average of all normal RR intervals, expressed in milliseconds) $[13,15]$.

According to Goldenberg 2006 [29], 30-second segments are adequate to form heart rate windows analysis of RMSSD index to evaluate the parasympathetic reactivation after exercise. Thus, to complement the analysis in the immediate recovery and assess whether the heart rate window size influenced the HRV indices, the RMSSD index was calculated in the following periods: initial rest [30 seconds during the 10 minutes (TO)], exercise [30 seconds during the second series of the protocol (T1) and recovery [2 minutes, divided into four moments of 30 seconds, which was individually analyzed (T2, T3, T4 and T5].

In addition to these indices it was also analyzed the Poincaré plot, and the following indexes were extracted: SD1 (standard deviation of the variability instant beat-to-beat), SD2 (standard deviation of long-term continuous RR intervals) and SD1/SD2 [15].

In relation to the frequency domain we used the spectral components of low (LF - 0.04 to $015 \mathrm{~Hz}$ ) and high frequency (HF - 0.15 to $0.40 \mathrm{~Hz}$ ) in $\mathrm{ms}^{2}$, and the ratio of these indices (LF/HF). Spectral analysis was calculated by using the Fast Fourier Transform algorithm [15, 17].

\section{Statistical analysis}

Gaussian distribution of the data was attested using the Shapiro-Wilks test. For comparisons between protocols (Endurance vs. Resistance) and moments (T0 vs. T1, T2, T3, T4, T5, T6) we applied two-way analysis of variance for repeated measures followed by the Bonferroni posttest for parametric distributions or Dunn's posttest for non-parametric data. The repeated-measures data were checked for sphericity violation using Mauchly's test and the Greenhouse-Geisser correction was conducted when the sphericity was violated. Significance level was set at $p<0.05$ for all tests. For statistical analysis we used the SPSS (version 13.0) software (SPSS Inc., Chicago, IL, USA).

\section{Results}

Figure 2, 3, 4, 5 and 6 show the behavior of HRV indices in time and frequency domains, respectively, rest, and recovery resistance and endurance protocols. There was a moment effect for the time domain indices (RMSSD and SDNN; $p=0.000$ ). No effects were observed between the protocols (RMSSD, $p=0.707$; SDNN, $p=0.883$ ) and in the moment and protocol interaction (RMSSD, $p=0.675$; SDNN, $p=0.742$ ). We noted that RMSSD (ms) was significantly increased at T0 (rest) compared to T3, T4, T5 and T6 of recovery in resistance protocols, while of recovery in endurance protocols this index was significantly increased at T0 (rest) compared to T5 and T6. Although the SDNN index (ms) was significantly increased at T0 (rest) compared to T3, T4, T5 and $\mathrm{T} 6$ of recovery in endurance protocols, while of recovery in resistance protocol, these indices were significantly increased at T0 (rest) compared to T4, T5 and T6. In addition, figure 3 (RMSSD index (ms) 
Figure 2: Mean values followed by their standard deviations of the time-domain (RMSSD, SDNN indices), protocols of endurance and resistance.
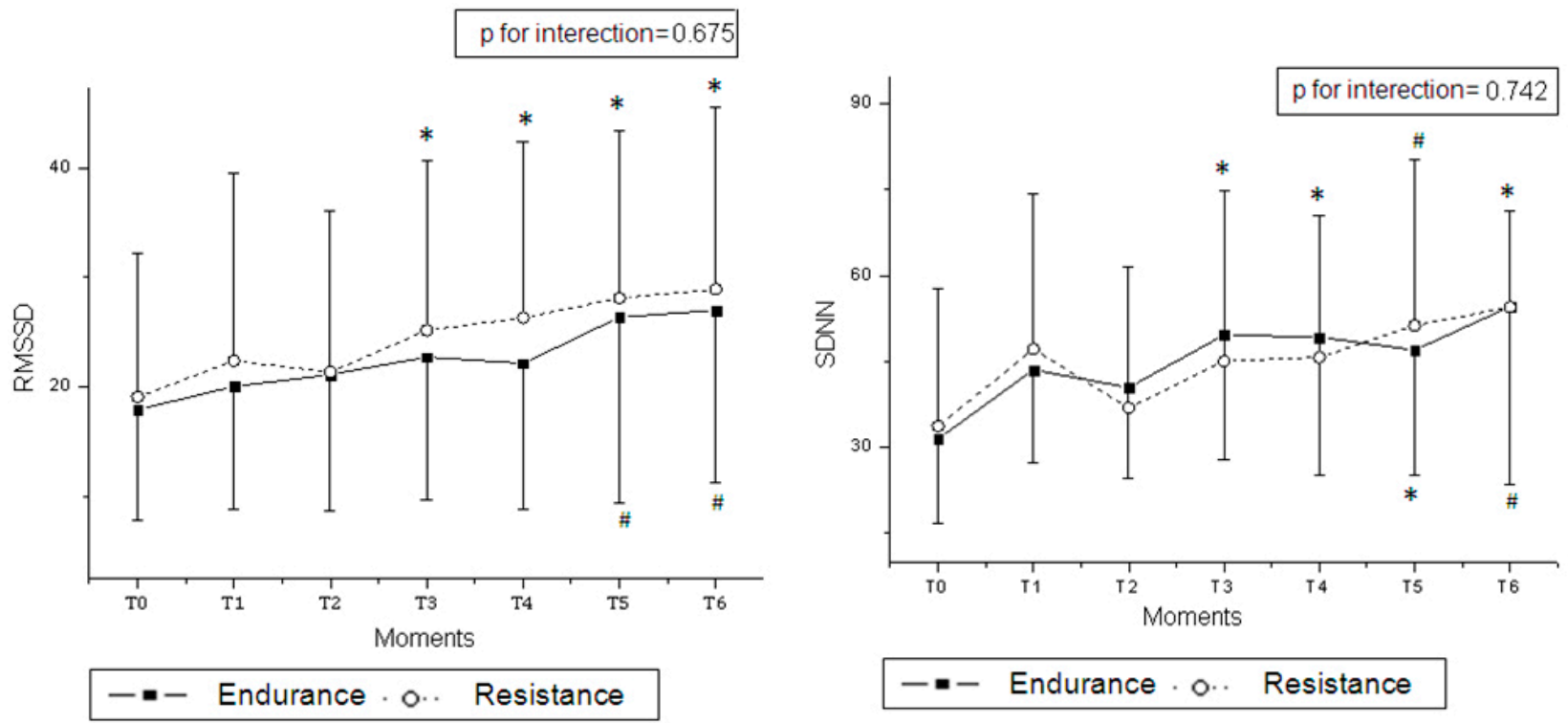

* Value with significant difference (Two-way analysis of variance for repeated measures followed by the Bonferroni posttest; $p<0.05$ ).

\# Value with significant difference (Two-way analysis of variance for repeated measures followed by the Dunn's posttest; $p<0.05$ ). Abbreviations: RMSSD: root mean square of the squared differences between adjacent normal RR intervals

Figure 3: Mean values followed by their standard deviations, of the RMSSD index of 30 seconds of the protocols of endurance and resistance.



Abbreviations: RMSSD: root mean square of the squared differences between adjacent normal RR intervals
30') shows that there was no significant difference between the moments in both endurance and resistance protocols.

Figure 4 presents the behavior of the HRV indices in the time domains, SD1 and SD2 geometrics methods in rest, recovery resistance and endurance reprotocols. We observed effects of moment, between recovery and rest in the SD2 index $(p=0.009)$. It was significantly increased at T0 (rest) compared to T3, T4, T5 and T6 of recovery in endurance protocols, while recovery in resistance protocols these indices were significantly increased at T0 (rest) compared to T4, T5 and T6. The analyses index SD1 did not show significant differences between the moments (rest and recovery) in both protocols, or relative compared protocols, and also interactions between moments and protocol.

Likewise, we observed moment effect on all indices in the frequency domain $(p=0.000)$. No effects were observed for those indices between the protocols [LF $\left(\mathrm{ms}^{2}\right), \mathrm{p}=0.651$; $\mathrm{HF}\left(\mathrm{ms}^{2}\right), \mathrm{p}=$ $0.610 ;$ LF/HF ratio $(p=0.355)]$. There were no interactions between moment and protocol $\left[\mathrm{LF}\left(\mathrm{ms}^{2}\right)\right.$, 
Figure 4: Mean values and followed by their standard deviations of the indices in the time domain, geometrical methods indices (SD1 SD2), protocols of endurance and resistance.
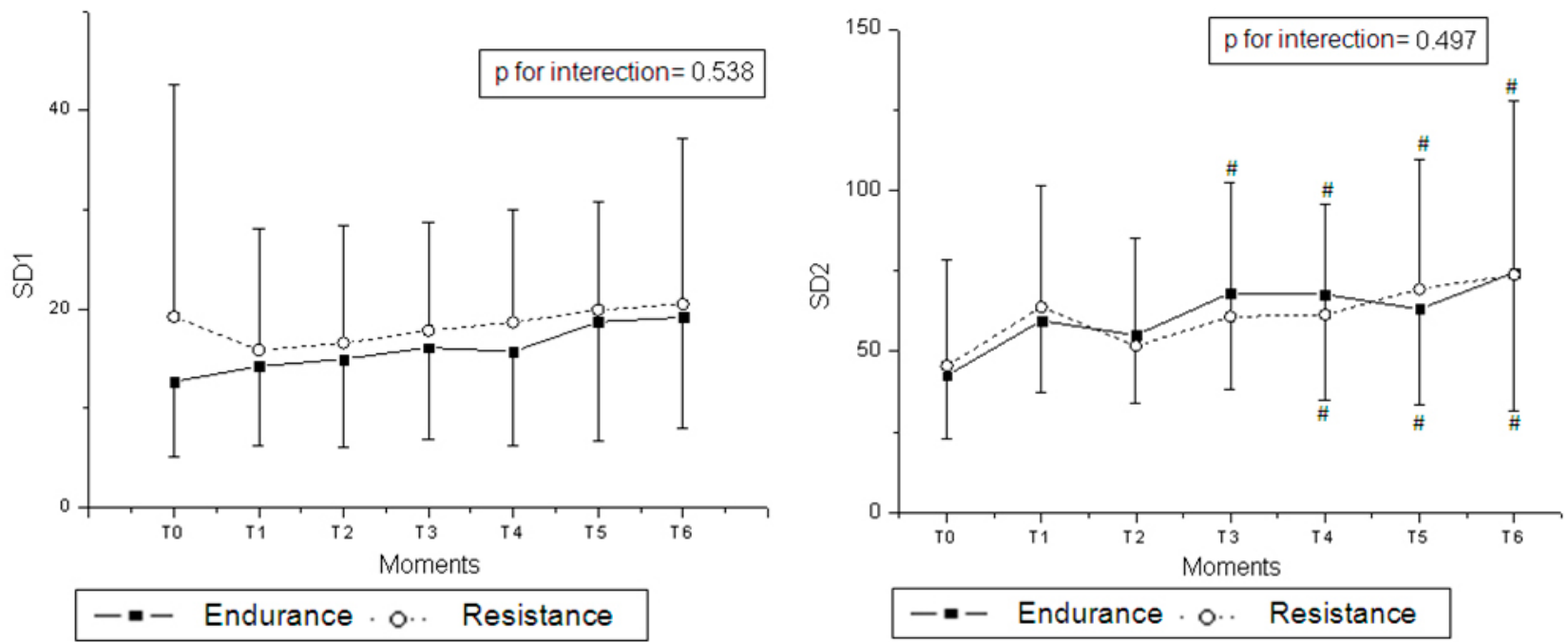

Value with significant difference (Two-way analysis of variance for repeated measures followed by the Dunn's posttest; $p<0.05$ ). Abbreviations: SD1 = standard deviation of instantaneous beat-to-beat variability SD2 = standard deviation of long-term continuous RR intervals.

$\mathrm{p}=0.635 ; \mathrm{HF}\left(\mathrm{ms}^{2}\right), \mathrm{p}=0.420 ;$ LF/HF ratio, $\mathrm{p}=$ 0.314]. Regarding the comparison between moments, we observed that $\mathrm{HF}\left(\mathrm{ms}^{2}\right)$ was significantly higher at T0 (rest) compared to T6 of recovery in endurance protocols, though in exercise and resistance protocols this index was significantly higher at T0 (rest) compared to T3, T4, T5, and T6 of recovery. LF $\left(\mathrm{ms}^{2}\right)$ was significantly higher at T0 (rest) compared to T3, T4, T5 and T6 of recovery in both protocols (Figure 5). The LF/HF index was significantly higher at T0 compared T3, T4 and T6 of recovery in endurance protocols.

Figure 5: Mean values and followed by their standard deviations of the frequency domain indices (HF and LF) in milliseconds $\left(\mathrm{ms}^{2}\right)$ protocols of endurance and resistance.
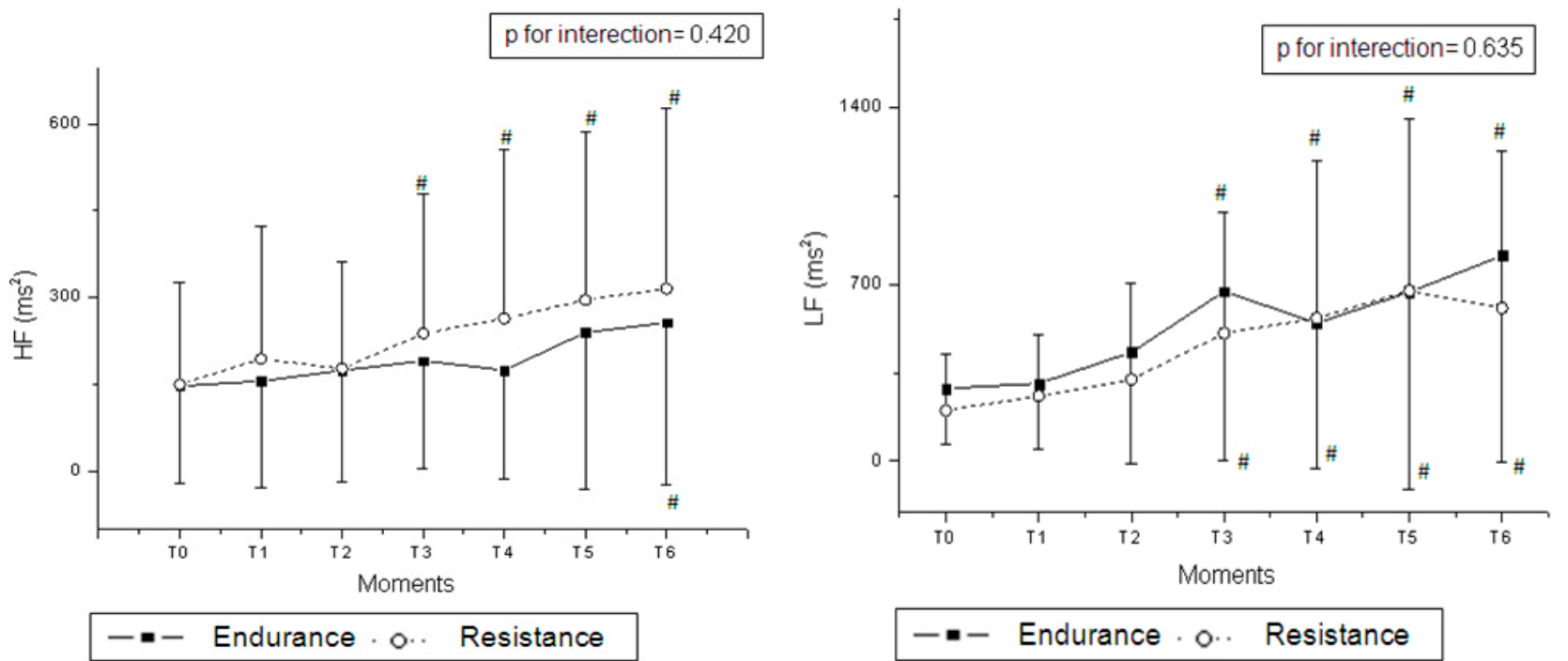

\#Value with significant difference (Two-way analysis of variance for repeated measures followed by the Dunn's posttest; $p<0.05$ ). Abbreviations: LF = low frequency component in miliseconds; $\mathrm{HF}=$ high frequency component in miliseconds. 
Figure 6: Mean values and followed by their standard deviations of the ratio between the indices of time domain and frequency domain (SD1/SD2 and LF/HF) protocol endurance and resistance.
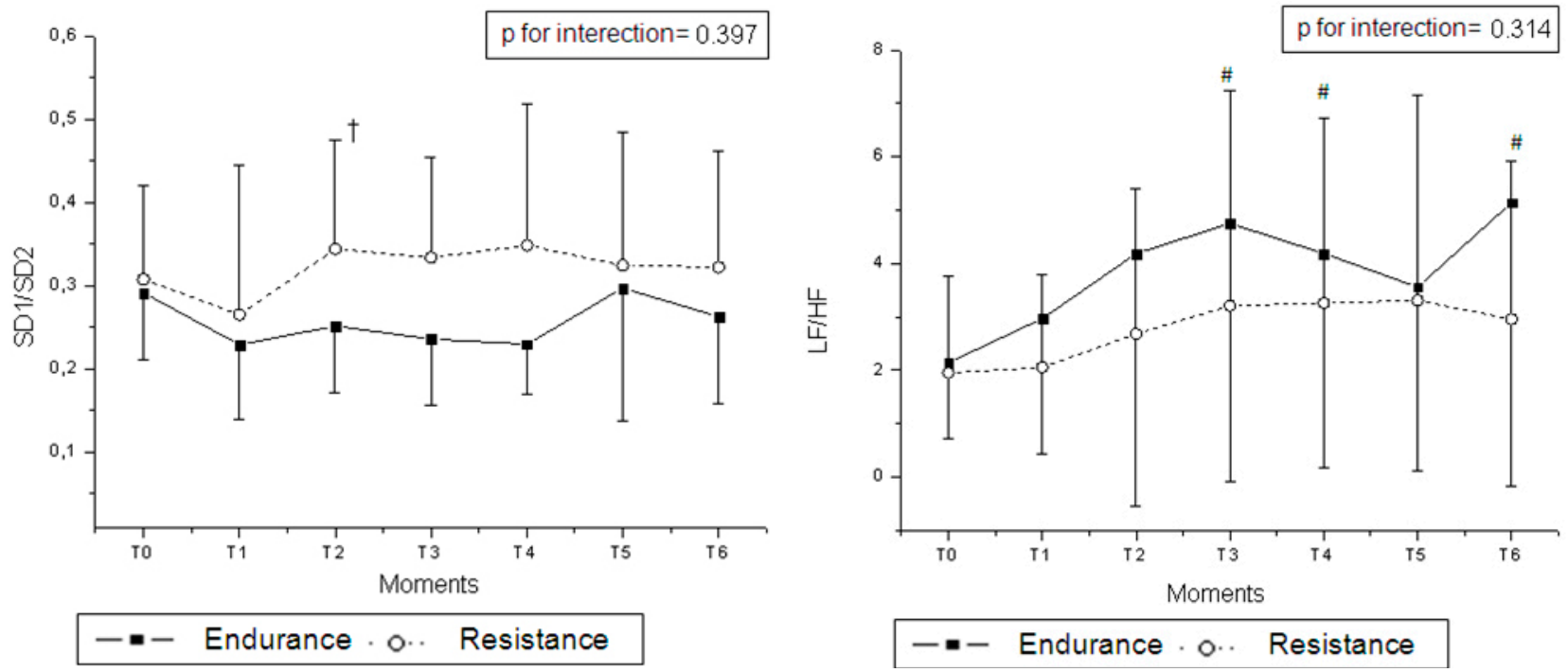

Value with significant difference (Two-way analysis of variance for repeated measures followed by the Dunn's posttest; $p<0.05$ ). Abbreviations: SD1/SD2 = ratio SD1 and SD2 indices; $\mathrm{LF} / \mathrm{HF}=$ ratio $\mathrm{LF}$ and $\mathrm{HF}$

Figure 6 presents the behavior of the SD1/SD2 ratio geometric index $(p=0.044)$ and the LF/HF index. The SD1/SD2 index did not show significant differences between moments (rest and recovery) in both endurance and resistance protocols, and also interactions between moments and protocol.

\section{Discussion}

In this study, the endurance and resistance protocols influenced the cardiac autonomic modulation, which presented increases in HRV indices during the recovery period compared with rest. Changes were noted in the indices that indicate parasympathetic activity after 40 minutes of recovery and also in the indices that represent overall HRV and sympathetic activity after 20 minutes in the endurance protocol. In relation to the resistance protocol, differences were observed in RMSSD, HF and LF $\left(\mathrm{ms}^{2}\right)$ from 20 minutes of recovery and in SDNN and SD2 from 40 minutes of recovery. When we compared the protocols, a significant difference was observed only in the second window of recovery for SD1/SD2. However, immediately after the implementation of both protocols no changes were observed.

Based on our data, the increase in HRV indices after 20 minutes indicates an improvement of the overall variability. Increases in HRV indices after acute endurance exercise in athletes with different intensities, even after the restoration of the index values were also observed in studies of Kaikonen et al [30] and Casties et al [28].

Such increases may be attributed to a late effect of the resistance exercise, as well as the relaxation response during the first hour of recovery, which in general may be associated with the respiratory sinus arrhythmia in consequence of reduced respiratory cycles [30-32]. Therefore, further studies with control breaths could be important to clarify whether changes in cardiac autonomic modulation are, in fact, result from the application of resistance exercise.

The protocols used in our study had different profile regarding the number of repetitions and load, inducing differences in the duration of the execution, since the rhythm of repetitions performed and the intervals of recovery between sets were monitored in both situations. Even with differences in intensity, the protocols were not sufficient to influence the cardiac autonomic modulation immediately after the end of the protocol.

According to our data, there was no significant difference in the autonomic variables between rest and the first two recovery moments of ten minu- 
tes and the 30-second moments. However, a previous study analyzed autonomic variables in young healthy individuals during and after acute resistance exercise and observed a fast return to baseline (30 seconds) [33]. Furthermore, Lamotte et al. [34] observed that the recovery period of up to 1 minute in cardiopathic patients was sufficient for heart rate and blood pressure restoration to values close to rest, when resistance exercise were performed.

A possible explanation for the absence of autonomic changes immediately after exercise may be related to autonomic dysfunction presented by the volunteers prior to the study, as a result of their cardiac disorder. The literature presents convergent conclusions regarding the reduced response of cardiac autonomic modulation in cardiopathic subjects compared with healthy age-matched subjects at rest and after autonomic nervous system stimulus $[35,36]$. These studies characterize the autonomic dysfunction by decreasing SDNN and RMSSD indices and increasing LF and LF/HF ratio, indicating a predominance of sympathetic activity. The values of LF and LF/HF ratio at rest and during the recovery period observed in the cardiopathic patients point to a sympathetic predominance and, thus, to autonomic dysfunction, corroborating the data reported in the literature above. We believe that, this autonomic dysfunction may have contributed to the absence of autonomic changes in the immediate implementation of the exercise.

Therefore, the specific profile of resistance exercise as its short period or the presence of autonomic dysfunction in these subjects are factors that may explain the absence of autonomic changes observed immediately after exercise. The absence of a healthy age-matched control group does not allow us to safely suggest that this lack of response is related to autonomic dysfunction presented by cardiopathic subjects, which represents a limitation of the study. Furthermore, due to the inclusion criteria, the sample size was small and it must also be considered as a limitation of the study.
Our results indicated that acute resistance exercise at different intensities did not change immediately the cardiac autonomic regulation. We did not observe muscle or cardiovascular complications in cardiopathic patients, which corroborate other studies $[1,3,7,8]$ regarding the safety of resistance exercise for this population.

Future studies that link the modulation of autonomic responses and clinical manifestations to the chronic or acute effects of resistance exercise may help to improve the control and safety processes, as well as to clarify the influence of resistance exercise on cardiovascular function improvement and clinical prognosis.

An acute bout of resistance exercise with different intensities did not change the cardiac autonomic modulation in the first 20 minutes of recovery. The HRV indices were increased at the recovery period compared with the rest.

\section{Acknowledgements}

"We thank Dr. Hani Atrahs for his kind help with English Grammar and Spelling" and Fapesp. Fundação de Amparo à Pesquisa do Estado de São Paulo. Process: 2014/12150-0

\section{Competing interest}

The authors declare that they have no competing of interest.

\section{List of abbreviations}

ANS: autonomic nervous system

HRV: heart rate variability

BMI: body mass index

BP: Blood pressure

HR: heart rate

1RM: one-repetition maximum test

RMSSD: root mean square of the squared differences between adjacent normal RR intervals in a time interval, expressed in milliseconds 
SDNN: standard deviation of the average of all normal RR intervals, expressed in milliseconds

SD1: standard deviation of the variability instant beat-to-beat

SD2: standard deviation of long-term continuous RR intervals

SD1/SD2: ratio SD1 and SD2 indices

$\mathrm{HF}=$ high frequency component in miliseconds

$L F=$ low frequency component in miliseconds

$\mathrm{LF} / \mathrm{HF}=$ ratio $\mathrm{LF}$ and $\mathrm{HF}$

TO: rest

T1: from 0 to 10 minutes of recovery

T2: from 10 to 20 minutes of recovery

T3: from 20 to 30 minutes of recovery

T4: from 30 to 40 minutes of recovery

T5: from 40 to 50 minutes of recovery

T6: from 50 to 60 minutes of recovery

\section{References}

1. Marzolini S, Oh P, Thomas SG, Goodman JM (2008) Aerobic and resistance training in coronary disease: single versus multiple sets. Med Sci Sports Exerc 40(9): 1557-1564.

2. Williams MA, Haskell WL, Ades PA, Amsterdam EA, Bittner V, Franklin BA et al (2007) Resistance exercise in individuals with and without cardiovascular disease: 2007 Update - A scientific statement from the American Heart Association council on clinical cardiology and council on nutrition, physical activity, and metabolism. Circulation 116:1081-1093. doi: 10.1161/ CIRCULATIONAHA.107.185214

3. Goel K, Lennon RJ, Tilbury T, Squires RW, Thomas RJ (2011) Impact of Cardiac Rehabilitation on Mortality and Cardiovascular Events After Percutaneous Coronary Intervention in the Community. Circulation 123:2344-2352. doi: 10.1161/ CIRCULATIONAHA.110.983536

4. Ghroubi S, Chaaria M, Elleucha $H$, Massmoudib K, Abdenadherc M, Trabelssid I, et al (2007) The isokinetic assessment of peripheral muscle function in patients with coronary artery disease: correlations with cardiorespiratory capacity. Ann Réadapt Med Phys 50:295-301. doi: http://dx.doi.org/10.1016/j. annrmp.2007.03.012

5. Okada Y, Toth MJ, VanBuren P (2008) Skeletal muscle contractile protein function is preserved in human heart failure. J Appl Physiol 104: 952-957.

6. Baum K, Hildebrandt U, Edel K, Bertram R, Hahmann H, Bremer FJ, et al (2009) Comparison of skeletal muscle strength between cardiac patients and age-matched healthy controls. Int J Med Sci 6:184-191. doi: doi:10.7150/ijms.6.184

7. Thompson WR eds (2007) ACSM's guidelines (American College of Sports Medicine) for exercise testing \& prescription. $8^{\text {a }}$ ed. Wolters Kluwers/Lippincott Willians \& Wilkins.

8. Vincent KR, Vincent HK (2006) Resistance training for individuals with cardiovascular disease. J Cardiopulm Rehabil 26: 207-216.

9. Adams J, Cline M, Reed M, Masters A, Ehlke K, Hartman J (2006) Importance of resistance training for patients after a cardiac event. Proc (Bayl Univ Med Cent) 19: 246-248.

10. Gunn E, Smith KM, McKelvie RS, Arthur HM (2006) Exercise and the heart failure patient: aerobic vs strength training - Is there a need for both? Prog Cardiovasc Nurs 21: 146-150.

11. Heffernan KS, Kelly EE, Collier SR, Fernhall B (2006) Cardiac autonomic modulation during recovery from acute endurance versus resistance exercise. Eur J Cardiovasc Prev \& Rehabil13:80-86. doi: 10.1097/01.hjr.0000197470.74070.46

12. Leite PH, Melo RC, Mello MF, Silva E, Borghi-Silva A, Catai A M (2010) Heart rate responses during isometric exercises in patients undergoing a phase III cardiac rehabilitation program. Rev Bras Fisioter 14(5):383-9. doi: http://dx.doi.org/10.1590/ S1413-35552010000500006

13. Zuttin RS, Moreno MA, César MC, Martins LE, Catai AM, Silva E (2008) Evaluation of autonomic heart rate modulation among sedentary young men, in seated and supine postures. Rev Bras Fisioter 12(1): 7-12. doi: http://dx.doi.org/10.1590/S141335552008000100003.

14. Vanhees L, Stevens A, Schepers D, Defoor J, Rademakers F, Fagard R (2004) Determinants of the effects of physical training and of the complications requiring resuscitation during exercise in patients with cardiovascular disease. Eur J Cardiovasc Prev \& Rehabil 11(4): 304-12.

15. Vanderlei LCM, Pastre CM, Hoshi RA, Carvalho TD, Godoy, MF (2009) Basic notions of heart rate variability and its clinical applicability. Rev Bras Cir Cardiovasc 24(2): 205-217. doi: http:// dx.doi.org/10.1590/S0102-76382009000200018

16. Lopes FL, Pereira FM, Reboredo MM, Castro TM, Vianna JM, Novo Jr JM, et al (2007) Heart rate variability and strength training. Rev Bras Fisioter 11(2):101-6. doi: http://dx.doi. org/10.1590/S1413-35552007000200005

17. Martinmäki K, Rusko H (2008) Time-frequency analysis of heart rate variability during immediate recovery from low and high intensity exercise Eur J Appl Physiol 10(2): 353-360.

18. Barbosa MM, Nunes MCP, Campos Filho O, Camarozano A, Rabischoffsky A, Maciel BC, et al (2009). Sociedade Brasileira de Cardiologia. Diretrizes das Indicações da Ecocardiografia. Arq Bras Cardiol 93(6 supl.3):e265-e302. doi: http://dx.doi. org/10.1590/S0066-782X2009001500001 
19. Andrade JP, ed (2010) VI Diretrizes Brasileiras de Hipertensão. Arq Bras Cardiol 95(1 supl.1): 1-51. doi: http://dx.doi.org/10.1590/ S0066-782X2010001700001

20. Assunção WD, Daltro M, Simão R, Polito M, Monteiro W (2007) Acute cardiovascular responses in strenght training conducted in exercises for large and small muscular groups. Rev Bras Med Esporte 13(2): 118-22. doi: http://dx.doi.org/10.1590/S151786922007000200010

21. Geraldes AAR, Barbosa GCM, Oliveira DWL, Carvalho J, Farinatti PTV (2008) Relationship between knee extensor muscle strength and different gait speeds. Rev Bras Educ Fís Esp 22(3): 173-81.

22. Barros MAP, Sperandei S, Jr Silveira PCS, Oliveira CG (2008) Reproducibility in the maximal repetition test in the lat pulldown exercise for men. Rev Bras Med Esporte 14(4):348-52. doi: http://dx.doi.org/10.1590/S1517-86922008000400005.

23. Okano AH, Cyrino, Nakamura FY, Guariglia DA, Nascimento MA, Avelar A et al (2008) Behavior of the muscle strength and arm muscle area during 24 weeks of weight training. Rev Bras Cineantropom Desempenho Hum 10(4): 379-385.

24. Mastrocolla LE, ed. (1995) Consenso Nacional de Ergometria. Arq Bras Cardiol 65(2): 191-211.

25. Vanderlei LCM, Silva RA, Pastre CM, Azevedo FM, Godoy MF (2008) Comparison of the Polar S810i monitor and the ECG for the analysis of heart rate variability in the time and frequency domains. Braz J Med Biol Res 41(10):854-859. doi: http://dx.doi. org/10.1590/S0100-879X2008005000039

26. Godoy MF, Takakura IT, Correa PR (2005) The relevance of nonlinear dynamic analysis (Chaos Theory) to predict morbidity and mortality in patients undergoing surgical myocardial revascularization. Arq Cienc Saúde 12(4): 167-71.

27. Niskanen JP, Tarvainen MP, Ranta-aho PO, Karjalainen PA (2004) Software for advanced HRV analysis. Comput Methods and Programs in Biomed 76:73-81. doi:10.1016/j.cmpb.2004.03.004

28. Casties JF, Mottet D, Le Gallais D (2006) Non-linear analyses of heart rate variability during heavy exercise and recovery in cyclists. Int J Sports Med 27:780-785. doi: 10.1055/s-2005872968

29. Goldberger JJ, Le FK, Lahiri M, Kannankeril PJ, Ng J, Kadish $\mathrm{AH}$ (2006) Assessment of parasympathetic reactivation after exercise. Am J Physiol Heart Circ Physiol 290: H2446-H2452. doi: 10.1152/ajpheart.01118.2005

30. Kaikkonen P, Rusko H, Martinma K (2008) Post-exercise heart rate variability of endurance athletes after different highintensity exercise interventions. Scand J Med Sci Sports 18:511519. doi: 10.1111/j.1600-0838.2007.00728.x

31. Barak OF, Jakovljevic DG, Gacesa JZP, Ovcin ZB, Brodie DA, Grujic NG (2010) Heart rate variability before and after cycle exercise in relation to different body positions. J Sports Sci Med 9: 176-182.

32. Pal GK, Velkumary S, Madanmohan (2004) Effect of shortterm practice of breathing exercises on autonomic functions in normal human volunteers. Indian J Med Res 120: 115-21.
33. Paschoa DC, Coutinho JFS, Almeida MB (2006) Análise da variabilidade da frequência cardíaca no exercício de força. Rev SOCERJ19(5): 385-90.

34. Lamotte $M$, Niset $G$ and Borne $P$ van de (2005) The effect of different intensity modalities of resistance training on beat-tobeat blood pressure in cardiac patients. Eur J Cardiovasc Prev Rehabil 12:12-17. doi:10.1097/01.hjr.0000159275.96437.c7

35. Rosenwinkel ET, Bloomfield DM, Arwady MA, Goldsmith RL (2001) Exercise and autonomic function in health and cardiovascular disease. Cardiol Clin 19(3): 369-87.

36. Montano N, Porta A, Cogliati C, Costantino G, Tobaldini E, Casali KR, Iellamo F (2009) Heart rate variability explored in the frequency domain: A tool to investigate the link between heart and behavior. Neurosci and Biobehav Rev 33: 71-80. doi: http:// dx.doi.org/10.1016/j.neubiorev.2008.07.006

\section{Comment on this article:}

\section{Qf $[$ in $8+\mathbf{S}$ P}

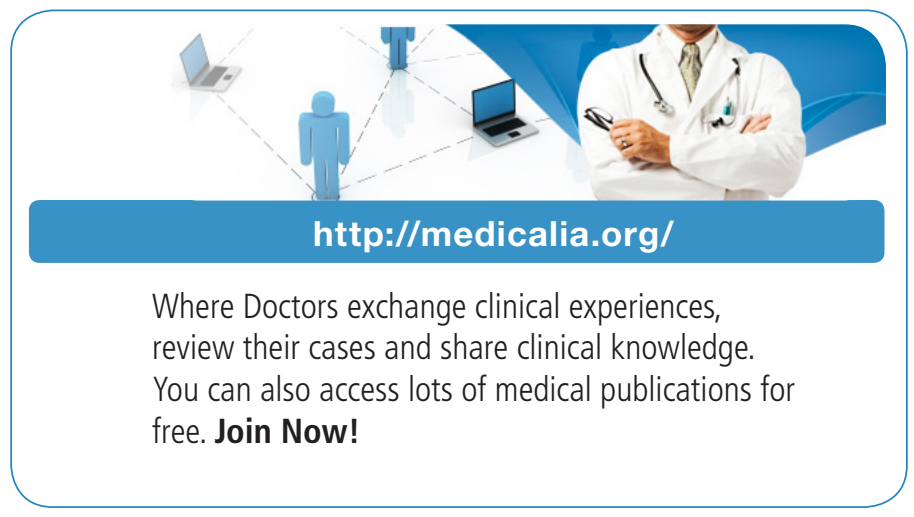

Publish with iMedPub

\section{http://www.imed.pub}

International Archives of Medicine is an open access journal publishing articles encompassing all aspects of medical science and clinical practice. IAM is considered a megajournal with independent sections on all areas of medicine. IAM is a really international journal with authors and board members from all around the world. The journal is widely indexed and classified Q1 in category Medicine. 